\title{
Influence of Porosity and Alloy addition on the Wear behaviour of a Sinter- Forged C45 Steel using Taguchi method
}

\author{
E. Naveen ${ }^{1}$ \\ Department of Mechanical Engineering, \\ Sri Sairam Engineering College, \\ Chennai, Tamilnadu, India \\ irumbalayar@gmail.com ${ }^{1}$
}

\author{
Sripada Raghavendra K $\mathbf{N}^{2}$ \\ Department of Mechanical, Industrial and Aerospace \\ Engineering, \\ Concordia University \\ Montreal, QC, Canada \\ srirajji@gmail.com²
}

\begin{abstract}
Elemental powders of Atomized Iron (Fe), Carbon (C) and Molybdenum (Mo) were weighed and mixed in a pot mill to yield the composition of $\mathrm{C} 45, \mathrm{C} 45-1 \% \mathrm{Mo}$ and $\mathrm{C} 45$ $2 \%$ Mo Steels, then compacted and sintered. The Sintered preforms had a density- $75 \%$ of the Theoretical Density. Then the Sintered preforms were subjected to densification to get two densities- $80 \%$ and $85 \%$ of the theoretical density through Forging. The sintered and densified preforms of alloy steels are subsequently machined to get the required test specimens. The experiments were conducted on a pin-on-disc Tribometer, conforming to ASTM G99 standards, on a rotating EN32 disc. Using Minitab 16 software, the Dry Sliding wear experiments were planned using L27 Orthogonal Array. The \% Theoretical Density of the Specimens, \% Mo Addition, Load and Sliding Speed were taken as input parameters, mass loss was the output parameter. It was observed that the increasing density of alloy steels adversely affects the wear resistance of the alloy steels and mass loss is increased. It was found that the addition of Mo significantly improves the wear resistance of the alloy steels irrespective of the densities due to hard phase carbides present in the microstructure. Empirical correlations for mass loss with respect to input parameters had been developed using Regression Analysis. In the case of Mo added alloy, Mo particulates embedded between the ferrite-pearlite grains are observed from the microstructure.
\end{abstract}

Keywords- Powder Metallurgy, Wear, Sintered Steels

\section{INTRODUCTION}

Tribology is a field of science which applies an operational analysis to problems of great economic significance such as reliability, maintenance and wear of technical equipment ranging from household appliances to aircraft. Derived from the Greek word 'Tribos', which means sliding or rubbing, the term deals with friction, wear and lubrication of the interacting surfaces in relative motion. Wear is an inevitable phenomenon and occurs at all places where there exist interacting surfaces in relative motion such as gears, bearing, coupling, sealing, cams, clutches, etc. Wear is the major cause of material wastage and loss of mechanical performance and any reduction of which can result in considerable savings. Friction is the principle cause of wear and energy dissipation. It is estimated that one third of world's energy resources in present use is needed to overcome friction in one form or another. One effective way to friction and wear is lubrication. Another convenient method is to devise special Tribo materials, which is more wear resistant as well as economically affordable

\section{LITERATURE SURVEY}

Molinari and Straffelini [1] investigated the wear behaviour of $\mathrm{Fe}-\mathrm{C}-\mathrm{Ni}$-Mo and Fe-C-Mo steels in three states namely steam treated, sintered and heat treated (oil quenching and stress relieving). Due to their high resistance to plastic flow, the heat-treated steels exhibited lesser wear rates. Oxidative wear is commonly observed in all the three states. The Molybdenum alloyed steel had a higher wear resistance compared to the other steels due to the evenly distributed bainite structure. Molinari and Straffelini [2] investigated the dry sliding wear behaviour of sintered and steam treated $\mathrm{Fe}-2 \% \mathrm{Cu}$ and $\mathrm{Fe}-$ $0.3 \% \mathrm{C}$ alloy steels. They found that the wear rate is independent of the chemical composition of steels as long as the oxide layer forms on the outer surface and the wear rate is lesser. The Copper and Carbon alloyed steels exhibit improved wear resistance because to the domination of delamination wear mechanism. Wang and Danninger [3] found that the Sintering temperature affects the wear behaviour of sintered steels with $1 \%$ Carbon and 3.5\% Molybdenum addition. At a Lesser sintering temperature (11200C) the wear rate of the steels is lesser when compared with Steels subjected to the higher sintering temperature (12200C). Razavizadch and Davies [4] reported that the addition of copper as alloying element to iron based alloys significantly improves the wear resistance of the alloy steels due to predominant delamination wear process. Ceschini et al [5] have found that the increase in Molybdenum addition to $\mathrm{Fe}-\mathrm{C}$ steels and higher a sintering temperature lead to significant improvement in the sliding wear resistance of $\mathrm{Fe}-\mathrm{C}-\mathrm{Mo}$ because to the formation of bainite microstructure. Gopinath [6] studied the influence of speed on the wear of sintered iron-based materials. The wear rates of sintered $\mathrm{Fe}-\mathrm{Cu}$ alloys got reduced with increasing 
sliding speed upto a particular threshold value, after which the trend got reversed. Zhang et al [7] observed that the addition of Sulphur (S) to Fe-Mo alloy steels contributes to reduction of the wear rate due to the chemical reactions of Sulphur with Molybdenum, which leads to the formation of Sulphide of Molybdenum, which forms adherent film on the wear surface. Murakami et al [8] observed that the Fe-Mo Steel specimen exhibited higher wear resistance at the non-annealed state when compared to the annealed specimen of the same alloy steel because of higher fracture toughness and hardness. The formation of oxides of Molybdenum during the wear test lead to lower coefficient of friction. Adhesive wear mechanism was identified as the predominant in the wear of alloy steel. Tekeli et al [9] experimentally found that the wear rate of Annealed $\mathrm{Fe}-0.3 \% \mathrm{C}$ P/M steel, followed by water quenching was lower compared to that of as sintered state. This is due to the transformation of pearlite into martensite microstructure during quenching process. The wear mechanism found in the alloy specimen is a mixture of adhesive and abrasive wear due to high volume fraction of martensite in microstructure. Tekeli and Gural [10] have investigated the effect of microstructure and heat treatment on dry sliding wear behaviour of Sintered steels with $0.3 \%$ Carbon and $2 \%$ Nickel additions. They have experimentally found that the TemperedQuenched specimens had lower wear resistance when compared to the Inter-Critically Annealed specimens of same composition. It was due to the detachment of surface platelets (wear debris) by micro ploughing and subsequently the predominant abrasive wear mechanism is taking place on the surface. The specimens subjected to Lower Inter-Critical annealing temperature $(7280 \mathrm{C})$ exhibited lesser wear rate when compared to the specimens annealed at the higher InterCritical Annealing temperature $(9000$ C) due to the transformation of martensite from the rich austenite microstructure. Caloco et at [11] experimentally found that though the Laser Surface Melted- Sintered AISI M42 exhibited higher hardness when compared with as sintered AISI M42 specimens. The Laser Surface Melted- Sintered specimens exhibited poor wear resistance compared to sintered specimens. It was due to the complete elimination of residual porosity and formation of super saturated martensite that lead to the dominance of abrasive wear. Anton et al [12] found that the addition of $0.7 \%$ Carbon to plain carbon steels enhances their wear resistance when compared with $0.3 \%$ Carbon addition. They have also found that the addition of Manganese $(\mathrm{Mn})$ alone to the $0.7 \%$ Carbon steels showed improved wear behaviour than combined Nickel-Manganese addition, due to the formation of higher percentage of martensitic-bainitic structure in a ferritic-pearlitic matrix. Abrasion-adhesion wear mechanism was found to be dominant in these alloy steels, that lead to higher wear rates. Leheup et al [13] investigated the effect of density on wear behaviour of sintered iron specimens. They have experimentally found that the wear behaviour of the sintered preforms is dependent upon the sliding amplitude rather than the density. At the higher sliding amplitude, the higher density sintered preforms are subjected to the higher wear loss compared to the lower density specimens. Lim and Brunton [14] investigated the predominant wear mechanism of the Sintered and NonSintered steels were ploughing and delamination. The open pores on the sliding surfaces of sintered iron preforms acted as a site for the generation and collection of wear debris. Lim et al [15] have investigated the wear properties of unlubricated specimens of sintered and non-sintered medium and low carbon steels. They found that the wear behaviour of both the non-sintered and sintered steels were similar. Mild oxidation wear producing fine oxide debris and oxide plateau, with delamination as a secondary mechanism at higher load and speed has been reported. Kang [16] has investigated the wear behaviour of Copper based and Iron based sintered alloy materials. At mild sliding conditions $\mathrm{Cu}$-based alloy had better frictional properties. On the other hand, for the severe sliding conditions Fe-based sintered material was better. At the lower load condition, the softening effect of $\mathrm{Cu}$ in the $\mathrm{Cu}$-based alloy could prevent the wear without material transfer and the delamination wear is found predominant at the higher load and speed conditions. Dhanasekharan and Gnanamoorthy [17] found that the addition of Molybdenum Disulphide (MoS2 ) to $\mathrm{Fe}-\mathrm{C}-\mathrm{Cu}$ and $\mathrm{Fe}-\mathrm{C}-\mathrm{Cu}-\mathrm{Ni}$ Sintered Steels improves the wear behaviour of alloys.

\section{SPECIMEN PREPARATION}

Due to their high strength and hardness, the P/M Low alloy steels under the present study could be potential candidates for high-wear applications. Therefore, the need for studying their wear behaviour was strongly felt. Atomized powders of Iron (Fe), Carbon (Graphite Form) and Molybdenum (Mo) were weighed separately in a 4 decimal Mitutoyo Digital Balance. Then the powders were mixed according to their weight composition in pot mill and allowed to mix well for about 8 hours. Few drops of Liquid Paraffin was added as a binder to these powders. After 8 hours, the powders were taken out, weighed separately and packed for the preparation of each specimen. Compaction of premix was carried out at different pressures from $400 \mathrm{Mpa}$ to $600 \mathrm{Mpa}$ by using Hydraulic compacting press of capacity 100 tons. Aspect ratio for samples was maintained less than $1(\mathrm{~L} / \mathrm{D}<1)$. The Die \& Punch design and fabrication were carried accordingly, such that they should withstand the sufficient Load. A High Chromium High Carbon Steel Die was selected for the Compaction process as shown in Figure 3.1. The Die must me fixed and does not escape from the base plate while applying load. Initially the lower punch was inserted in the die case and placed properly in the base plate of hydraulic press. Zinc Stearate was applied over the die cavity, upper punch and lower punch. Powder was poured into the die cavity carefully. Load was applied after the contact has been made between the upper punch and upper plate of hydraulic press for the compaction of powders as shown in Figure 3.2. The load was applied gradually until required pressure has attained. After that the upper plate is moved upside and carefully the upper punch were removed for obtaining the Green Compact as shown in Figure 3.3. The Green Compact was given a coating 
to prevent it from oxidation. Sintering of the coated samples was carried out in a muffle furnace. Sintering furnace of rectangular cross section $\left(\max\right.$ Temp. $\left.1250^{\circ} \mathrm{C}\right)$ with a provision for necessary reducing atmosphere was chosen for Sintering, where the loosely packed Green Compact will be transformed into metallurgically bonded sample. Samples were placed in heating zone and heated to its sintering temperature $(\mathrm{Ts}=0.7-0.8$ Melting Point) as shown in Figure 3.4. In the first step of Sintering, the coating was removed and burned. This step is popularly known as 'de lube' or 'dewax' step. In the Second step the powder particles fuse together. The Third Step of the sintering cycle is the cooling step. Both sintering and cooling were done in controlled atmosphere. The details of the Sintering Parameters is given in Table 3.1. The Sintered Specimens had a Density about $75 \%$ of the theoretical density. Figure 3.5 shows the Sintered Specimens. Then the sintered specimens were subjected to densification through Forging. The specimens were subjected to two different loads in order to get two different densities for each alloy, namely $80 \%$ and $85 \%$ of theoretical density. The theoretical and the actual densities obtained, along with the Vicker's Hardness is given in Table 3.2

\begin{tabular}{|c|c|c|}
\hline S.No. & Sintering Parameters & Values \\
\hline 1 & $\begin{array}{c}\text { De-Lube/ De-Wax } \\
\text { temperature }\end{array}$ & $475 \pm 30^{\circ} \mathrm{C}$ \\
\hline 2 & Sintering temperature & $1100 \mathrm{C} \pm 10^{\circ} \mathrm{C}$ \\
\hline 3 & Sintering time & $120 \mathrm{~min}$ \\
\hline 4 & Cooling way & Furnace cooled \\
\hline 5 & Atmosphere used & Argon \\
\hline 6 & Gas Flow Rate & $0.4 \mathrm{~m}^{3} / \mathrm{hr}$ \\
\hline
\end{tabular}

Table 3.1: Sintering Parameters

\begin{tabular}{|c|c|c|c|c|}
\hline Specimen & $\begin{array}{c}\text { Theor } \\
\text { etical } \\
\text { Densit } \\
\mathbf{y} \\
\text { (g/cc) }\end{array}$ & $\begin{array}{c}\text { Actual } \\
\text { Density } \\
\text { (g/cc) }\end{array}$ & $\begin{array}{c}\% \\
\text { Densified }\end{array}$ & $\begin{array}{c}\text { Vicker's } \\
\text { Hardness } \\
\text { (HV) }\end{array}$ \\
\hline \multirow{3}{*}{ C45 } & \multirow[b]{3}{*}{7.7148} & 5.7861 & 75 & 87 \\
\hline & & 6.1718 & 80 & 120 \\
\hline & & 6.5575 & 85 & 170 \\
\hline \multirow[b]{2}{*}{ C45- } & \multirow[b]{2}{*}{7.7328} & 5.7996 & 75 & 94 \\
\hline & & 6.1862 & 80 & 134 \\
\hline
\end{tabular}

\begin{tabular}{|c|c|c|c|c|}
\hline $1 \%$ Mo & & 6.5728 & 85 & 154 \\
\hline \multirow{2}{*}{$\begin{array}{c}\text { C45- } \\
2 \% \mathrm{M} o\end{array}$} & \multirow{2}{*}{7.7534} & 5.8150 & 75 & 100 \\
\cline { 3 - 5 } & & 6.2027 & 80 & 140 \\
\cline { 3 - 5 } & & 6.5903 & 85 & 180 \\
\hline
\end{tabular}

Table 3.2: Theoretical, Actual Density \& Hardness of the Specimens

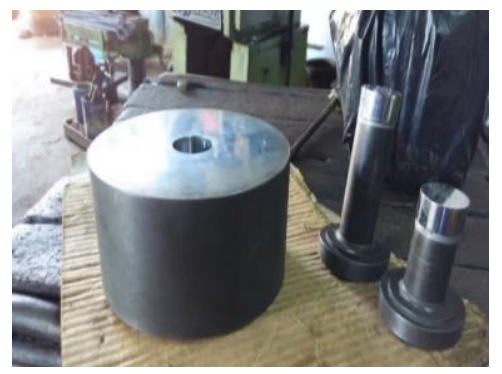

Fig 3.1 Die and Punch for Compaction

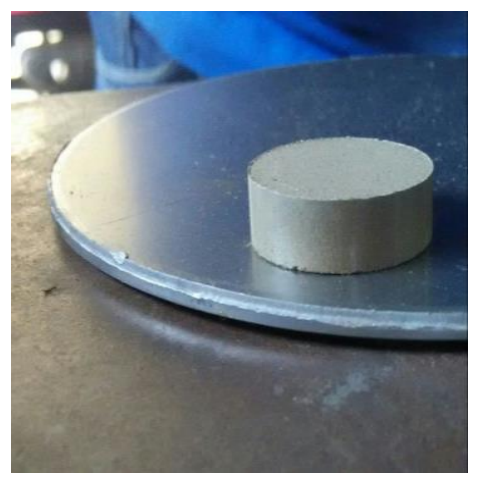

Fig 3.3: Green Compact

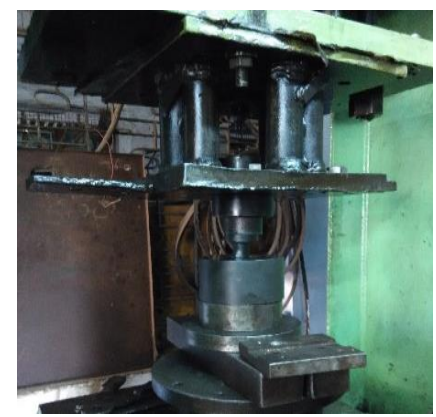

Fig 3.2: Load applied during Compaction

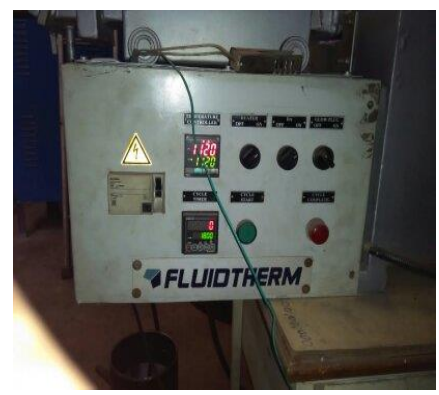

Fig 3.4: Sintering of Green Compact

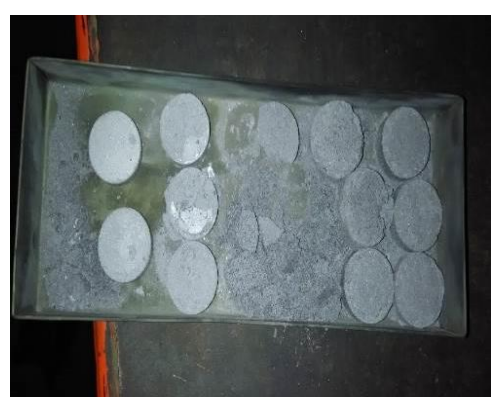

Fig 3.5: Sintered Specimens 


\section{WEAR TESTING}

In this work, a dry sliding wear behavior of P/M Steels were studied using a pin on-disc apparatus (DUCOM ${ }^{\mathrm{TM}}$ make). Figure 4.1 shows the arrangement of pin-on-disc apparatus. The disc material was made of EN-32 steel with a hardness of 65 HRC. The pin specimen is pressed against disc at a specified load usually by means of an arm and attached weights. The dry sliding wear tests were carried out at room temperature $\left(30^{\circ} \mathrm{C} \pm\right.$ $3^{\circ} \mathrm{C}$, RH $55 \% \pm 5 \%$ ) under dry sliding condition in accordance with the ASTM G 99 standard. Cylindrical pins of $10 \mathrm{~mm}$ diameter and $25 \mathrm{~mm}$ long were machined and polished by metallographic method. Immediately prior to testing, were cleaned and dried using acetone to remove all dirt and foreign matter from the specimens. Initial and final weight of the specimen was measured using a Mitutoyo ${ }^{\mathrm{TM}}$ make electronic weighing machine with an accuracy of 0.0001 grams. Wear measurement is carried out to determine the amount of materials removed (or worn away) after a wear test, (and in reality after a part in service for a period of time). The material worn away can be expressed either as weight (mass) loss, volume loss, or linear dimension change depending on the purpose of the test, the type of wear, the geometry and size of the test specimens, and sometimes on the availability of a measurement facility [4]. The specimen was fixed in the arm and the disc was made to rotate below the pin. Mass of the specimen before and after the test is measured using digital balance and mass loss is found out for each set of input parameters. Wear track images and SEM images were taken to analyze the maximum wear.
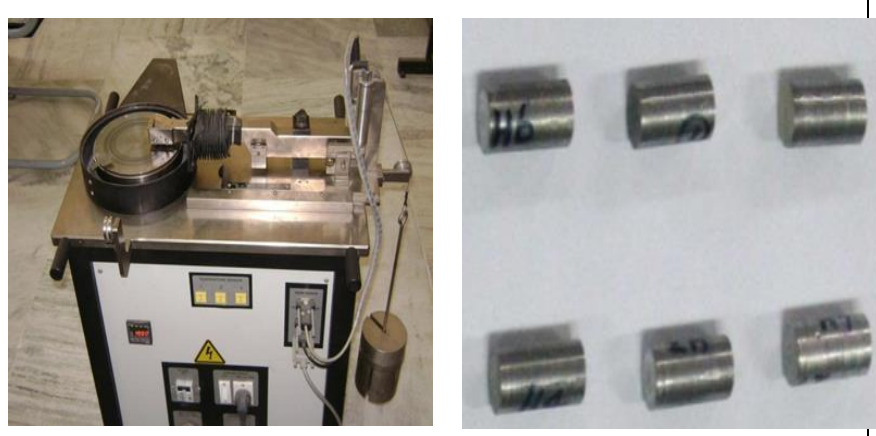

Fig 4.1 Pin-on-Disc Tribometer Fig 4.2: Wear Test Specimens Setup

\section{RESULTS AND DISCUSSIONS}

The Experiments were conducted according to the Taguchi' L27 Orthogonal Array- 3 level and 4 Factors. The Input 15 Parameters and their Levels is given in Table 5.1. The result of 16 the output parameter Mass loss is given in Table 5.2. Minitap 16 software was used for further analysis.

\begin{tabular}{|l|c|c|c|}
\hline $\begin{array}{c}\text { Input } \\
\text { Parameter }\end{array}$ & Level 1 & Level 2 & Level 3 \\
\hline $\begin{array}{l}\text { \% } \\
\text { Theoretical } \\
\text { Density }\end{array}$ & 75 & 80 & 85 \\
\hline $\begin{array}{l}\text { \% Mo } \\
\text { Addition }\end{array}$ & 0 & 1 & 2 \\
\hline Load (N) & 10 & 20 & 30 \\
\hline $\begin{array}{l}\text { Sliding } \\
\text { Speed (m/s) }\end{array}$ & 1 & 2 & 3 \\
\hline $\begin{array}{l}\text { Sliding } \\
\text { Distance (m) }\end{array}$ & \multicolumn{3}{|l|}{$3000 \mathrm{~m}$} \\
\hline
\end{tabular}

Table 5.1 Input parameters for Wear Test

Calculating the Signal-to-Noise ratio ( $\eta$ ) [5]: Mass Loss has to be minimized; it is smaller- the better type of quality characteristics. Hence, $\mathrm{S} / \mathrm{N}$ ratio for Mass Loss is computed from the following equation:

Smaller the better $\eta=-10 * \log \left(\frac{1}{n} * \sum_{i=1}^{n} y_{i j}^{2}\right)$

\begin{tabular}{|c|c|c|c|c|c|c|}
\hline${ }^{\text {S.No }}$ & $\begin{array}{c}\text { \% } \\
\text { Theoreti } \\
\text { cal } \\
\text { Density }\end{array}$ & $\begin{array}{c}\text { \% Mo } \\
\text { Additi } \\
\text { on }\end{array}$ & $\begin{array}{c}\text { Slidin } \\
\mathbf{g} \\
\text { Load }\end{array}$ & $\begin{array}{c}\text { Veloci } \\
\text { ty } \\
\text { (m/s) }\end{array}$ & $\begin{array}{c}\text { Mass Loss } \\
\text { (g) }\end{array}$ & S/N Ratio \\
\hline 1 & 75 & 0 & 10 & 1 & 0.4709 & 6.541426 \\
\hline 2 & 75 & 0 & 20 & 2 & 0.5351 & 5.431301 \\
\hline 3 & 75 & 0 & 30 & 3 & 0.5545 & 5.121969 \\
\hline 4 & 75 & 1 & 10 & 2 & 0.3369 & 9.44998 \\
\hline 5 & 75 & 1 & 20 & 3 & 0.3452 & 9.238584 \\
\hline 6 & 75 & 1 & 30 & 1 & 0.3943 & 8.083464 \\
\hline 7 & 75 & 2 & 10 & 3 & 0.2251 & 12.95249 \\
\hline 8 & 75 & 2 & 20 & 1 & 0.2542 & 11.89649 \\
\hline 9 & 75 & 2 & 30 & 2 & 0.2842 & 10.92752 \\
\hline 10 & 80 & 0 & 10 & 2 & 0.5724 & 4.846007 \\
\hline 11 & 80 & 0 & 20 & 3 & 0.5786 & 4.752431 \\
\hline 12 & 80 & 0 & 30 & 1 & 0.5839 & 4.67323 \\
\hline 13 & 80 & 1 & 10 & 3 & 0.4035 & 7.883129 \\
\hline 14 & 80 & 1 & 20 & 1 & 0.4556 & 6.828326 \\
\hline 15 & 80 & 1 & 30 & 2 & 0.4951 & 6.106141 \\
\hline ff 16 & 80 & 2 & 10 & 1 & 0.3320 & 9.577238 \\
\hline 17 & 80 & 2 & 20 & 2 & 0.3564 & 8.961246 \\
\hline 18 & 80 & 2 & 30 & 3 & 0.3800 & 8.404328 \\
\hline 19 & 85 & 0 & 10 & 3 & 0.6875 & 3.254546 \\
\hline 20 & 85 & 0 & 20 & 1 & 0.8944 & 0.969364 \\
\hline 21 & 85 & 0 & 30 & 2 & 0.9563 & 0.388117 \\
\hline 22 & 85 & 1 & 10 & 1 & 0.4249 & 7.434265 \\
\hline 23 & 85 & 1 & 20 & 2 & 0.4322 & 7.286305 \\
\hline 24 & 85 & 1 & 30 & 3 & 0.5481 & 5.222804 \\
\hline & & & & & & \\
\hline
\end{tabular}




\begin{tabular}{|l|l|l|l|l|l|l|}
\hline 25 & 85 & 2 & 10 & 2 & 0.4021 & 7.913319 \\
\hline 26 & 85 & 2 & 20 & 3 & 0.4263 & 7.405693 \\
\hline 27 & 85 & 2 & 30 & 1 & 0.4600 & 6.744843 \\
\hline
\end{tabular}

Table 5.2 Results of the Wear Test

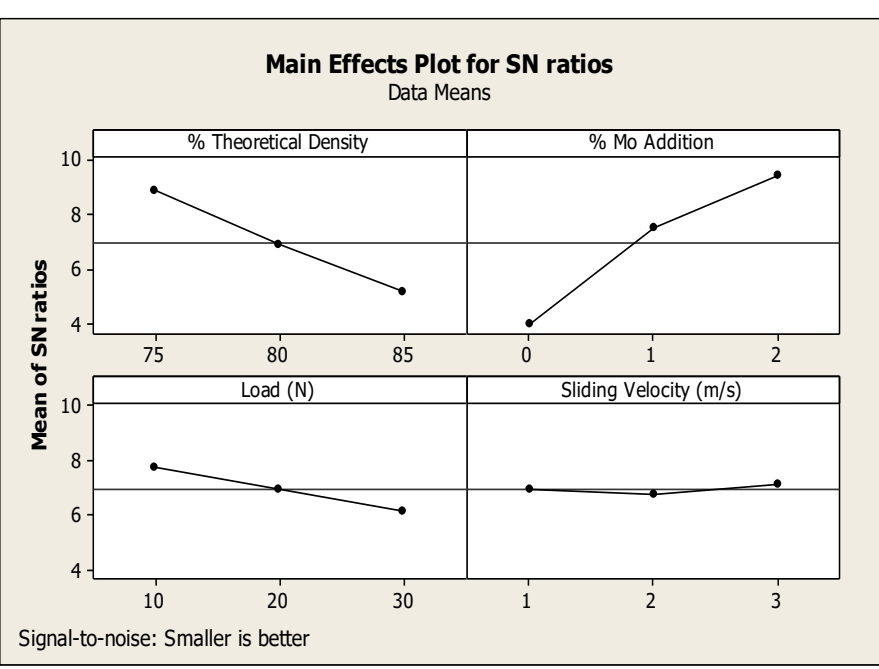

Fig 5.1: Main Effect Plots for S/N Ratios

\section{A. The regression equation}

Mass Loss $=3.17363-(0.0898507 * \%$ TD $)+(0.35593 \%$ Mo $)-(0.0257828 *$ Load $)+(0.151944 * S V)+(0.000704889 *$ $\% \mathrm{TD} * \% \mathrm{TD})+(0.0712389 * \% \mathrm{Mo} * \% \mathrm{Mo})-(2.46111 \mathrm{e}-005 *$ Load*Load $) \quad-(0.0179111 * \mathrm{SV} * \mathrm{SV}) \quad-\quad(90.00785467 *$ $\% \mathrm{TD} * \% \mathrm{Mo})+(0.000393511 * \% \mathrm{TD} * \mathrm{Load})$ $(0.00129911 * \%$ TD*SV $)-(0.00149511 * \%$ Mo*Load $)+$ $(0.00456444 * \% \mathrm{Mo} * \mathrm{SV})+\left(0.000616 \mathrm{Load}^{*} \mathrm{SV}\right)$

\section{$\mathrm{S}=\mathbf{0 . 0 7 0 0 9 1 2} \mathrm{R}-\mathrm{Sq}=\mathbf{9 2 . 1 6 \%} \mathrm{R}-\mathrm{Sq}(\mathrm{adj})=\mathbf{8 3 . 0 1 \%}$}

The lowering in wear rate of P/M Steels can be raised due to the addition of Molybdenum and which reduces the wear rate of the P/M Steels. The decrease in the Mass loss can also be correlated by role of Molybdenum as spacers that prevent direct contact between rough surfaces. The thermal mismatch between the Iron and Molybdenum increase the dislocation density that increases the resistance of the materials to plastic deformation. The formation of solid film Oxide and Sulphides of Molybdenum, makes the C45 Steel wear resistant. At a higher loads, the thermal softening and the plastic deformation tends to prevail. From the Table 5.3, it is very clear that the \% porosity (Inverse of \% Theoretical Density) also plays a significant role in reducing the Wear rate of both the Steels. It is due to the fact that the pores acts as site, where there are no material present, thereby reducing the Mass Loss considerably. For the lower density preforms, the plastic deformation of material can be accommodated by the pores by reducing the volume and subsequently the effective number of

asperities is getting reduced and makes the surface smooth. This in turn leads to the reduction in wear loss. In contrast, the plastic deformation with fewer pores in higher density preforms with asperities opposing on the surfaces, which in turn makes the specimen subjected to higher wear loss.

\begin{tabular}{|c|c|c|c|c|c|}
\hline Source & DF & Adj Ss & F & P & $\begin{array}{c}\text { \% } \\
\text { Contribution }\end{array}$ \\
\hline \%TD & 1 & 0.001177 & 0.2395 & 0.633379 & 24.79 \\
\hline \%Mo & 1 & 0.005237 & 1.0661 & 0.322195 & 54.41 \\
\hline Load & 1 & 0.002564 & 0.522 & 0.483838 & 4.74 \\
\hline SV & 1 & 0.000891 & 0.1813 & 0.677805 & 0.11 \\
\hline \% TD*TD & 1 & 0.001863 & 0.3793 & 0.549498 & 0.25 \\
\hline \%Mo*\%Mo & 1 & 0.03045 & 6.1981 & 0.028453 & 4.05 \\
\hline Load*Load & 1 & 0.000036 & 0.0074 & 0.932878 & 0 \\
\hline SV*SV & 1 & 0.001925 & 0.3918 & 0.543075 & 0.26 \\
\hline \%TD*\%Mo & 1 & 0.017352 & 3.532 & 0.08469 & 2.27 \\
\hline \%TD*Load & 1 & 0.004355 & 0.8865 & 0.364996 & 0.69 \\
\hline \%TD*SV & 1 & 0.000475 & 0.0966 & 0.761259 & 0.17 \\
\hline \%Mo*Load & 1 & 0.002515 & 0.5119 & 0.488012 & 0.33 \\
\hline \%Mo*SV & 1 & 0.000234 & 0.0477 & 0.830769 & 0.03 \\
\hline Load*SV & 1 & 0.000427 & 0.0869 & 0.773202 & 0.06 \\
\hline Error & 12 & 0.058953 & & & 7.84 \\
\hline Total & 26 & & & & 100 \\
\hline
\end{tabular}

Table 5.3: ANOVA table for $\%$ contribution of inputs for Mass Loss

\section{B. SEM Analysis Wear surface morphology of C45 Steels}

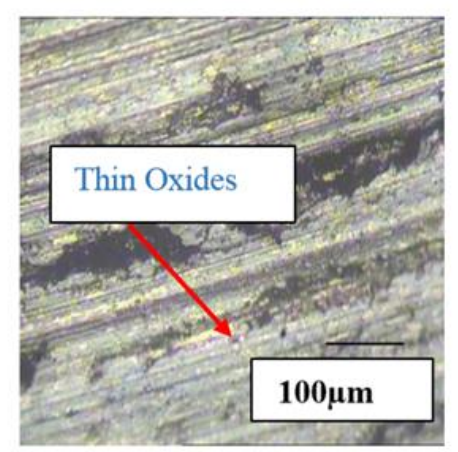

Fig 5.2.a C45 Steel-75\% TD

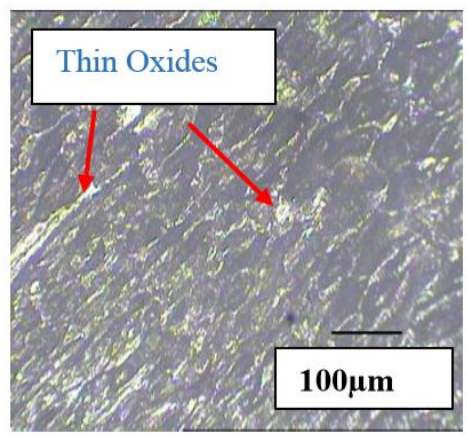

Fig 5.2.b C45 Steel-80\%TD 


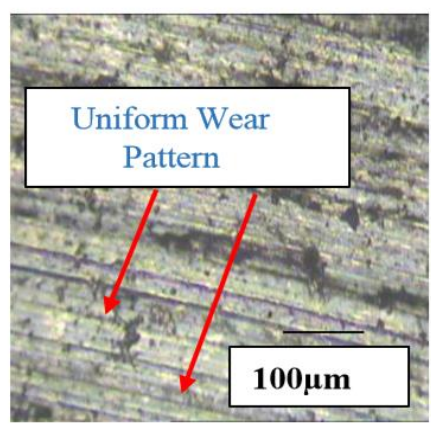

Fig 5.2.c C45 Steel-85\%TD

Figure 5.2.a, $\mathrm{b}$ and $\mathrm{c}$ shows the Optical Microscope images of Maximum Worn surfaces of C45 Steel at 75\%, 80\% and 85\% Theoretical Density (TD).

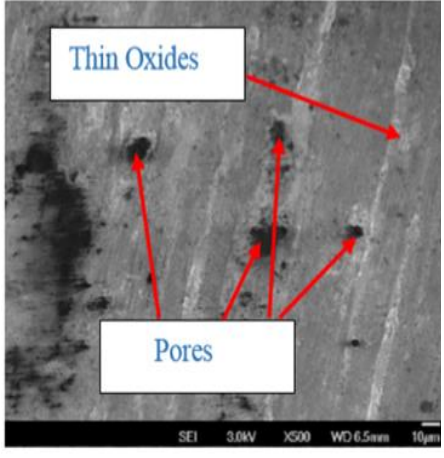

Fig 5.3.a C45 Steel-75\%TD

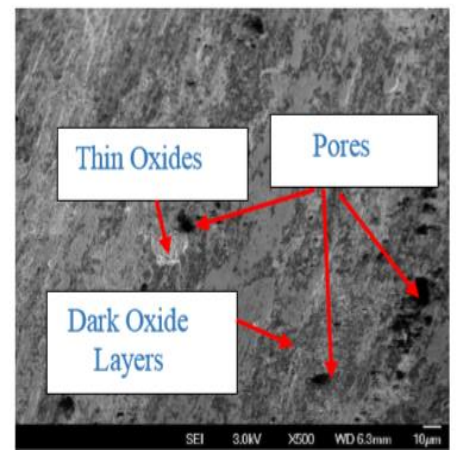

Fig 5.3.b C45 Steel-80\%TD

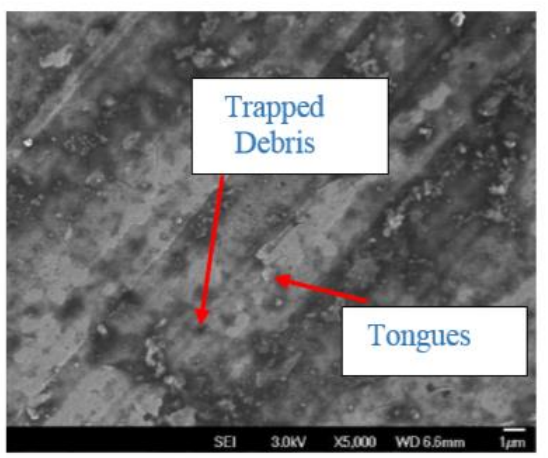

Fig 5.3.c C45 Steel-85\%TD

Figure 5.3.a, $\mathrm{b}$ and $\mathrm{c}$ shows the SEM images of Maximum Worn surfaces of C45 Steel at 75\%, 80\% and 85\% Theoretical Density(TD). It is observed that the C45 steel is subjected to uniform wear throughout the wear region and makes it uniform mass loss over the contact surface. The bright areas of thin oxide layer are visible throughout the entire wear surface micrograph and the dark areas are probably the areas fully covered by oxide [9]. The alternate white and dark areas may be the hill and groove of the wear track [10]. Few bright

particles are also observed in the image and this could be the metallic debris embedded in the pores [11]. As the plain carbon steels consists of soft ferritic-pearlitic structure, the wear loss is observed to be uniform [12]. This is evident from the uniform wear track of the surface. The wear loss is observed to be uniform. This is evident from the uniform wear track of the surface.

\section{SEM Analysis Wear surface morphology of C45-2\% Mo Steels}

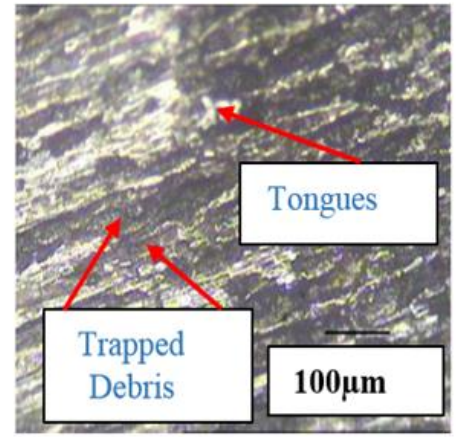

Fig 5.4.a C45-2\% Mo Steel Steel $75 \%$ TD

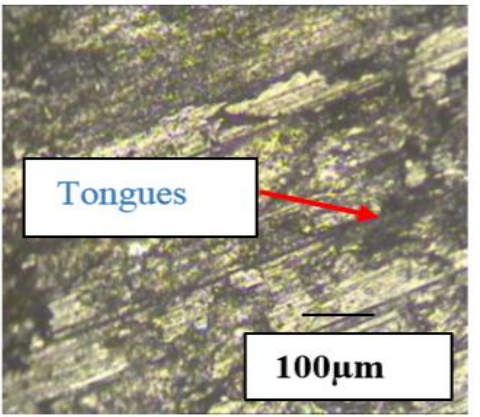

Fig 5.4.c C45-2\% Mo Steel-85\%TD

Figure 5.4.a, $\mathrm{b}$ and $\mathrm{c}$ shows the Optical Microscope images of Maximum Worn surfaces of C45-2\% Mo Steel at 75\%, 80\% and $85 \%$ Theoretical Density (TD).

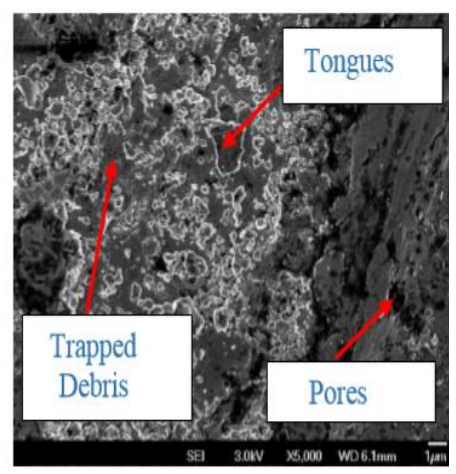

Fig 5.5.a C45-2\% Mo Steel $75 \% \mathrm{TD}$

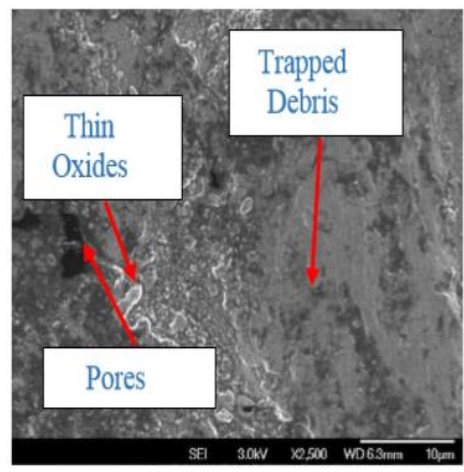

Fig 5.5.b C45-2\%Mo Steel $80 \%$ TD
Fig 5.4.b C45-2\% Mo $80 \%$ TD

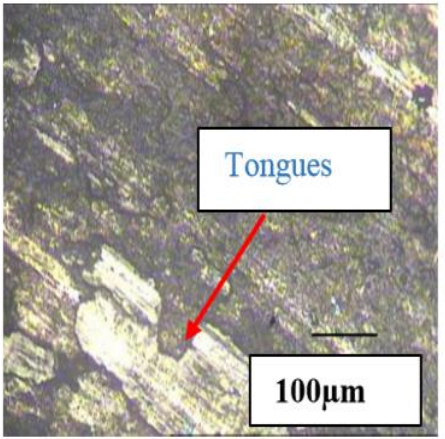

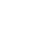




\section{REFERENCES}

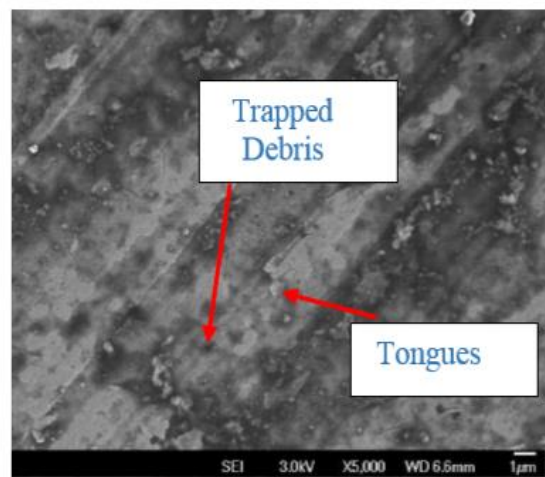

Fig 5.5.c C45-2\% Mo Steel-85\% TD

Figure $5.5 \mathrm{a}, \mathrm{b}$ and $\mathrm{c}$ shows the SEM images of Maximum Worn surfaces of $\mathrm{C} 45-2 \%$ Mo Steel at $75 \%, 80 \%$ and $85 \%$ Theoretical Density(TD). It is clearly evident from the SEM image of Mo alloyed steels that the layered appearance shows the removal of flakes due to delamination process [14]. The trapped wear asperities in the open pores, found in some places, significantly enhance the wear resistance of the alloy steel [14]. Appearance of tongues at some places in the SEM image could be the effect of deep metallic flow of steel due to deformation, which could further contribute to the reduction of wear rate of alloy steel and consequently enhance the friction at the interface [13]. The Wear of Mo alloyed steels, irrespective of densities is Non-Uniform.

\section{CONCLUSION}

The wear resistance is increased by addition of Molybdenum to C45 Steel. Irrespective of alloy steels as density increases wear resistance decreases and mass loss increases. The C45 Steel is found to undergo uniform wear due to the soft nature of the ferritic-pearlitic micro structure, while Mo alloyed steel is subjected to non-uniform surface wear due to the presence of hard particulates. Delamination is found to be a common mode of wear for carbon and alloy steels. Addition of Mo to plain carbon steel increases the hardness [16]. Hardness of As Sintered preforms is found to be decreased when compared to densified preforms. In the case of As Sintered preforms large no. of pores are observed when compared to densified preforms [17]. Confirmation Experiments were carried with the Empirical Equation obtained. The deviation from the Actual Readings were around $20 \%$.

\section{ACKNOWEDGEMENT}

The Authors are thankful to Mr.N.Ramanan, Senior EngineerR\&D Division, Sharda Motors Industries Ltd, ChengalpattuTamil Nadu State, India, for his valuable support and guidance throughout this work.
[1] Giovanni Straffelini, Alberto Molinari, "Dry sliding wear behaviour of steam treated sintered iron alloys", Wear 1992: 159, 127-134

[2] Giovanni Straffelini, Alberto Molinari, "Wear processes in highstrength sinteredalloys under dry rolling-sliding", Wear 1994: 173, 121-128

[3] Junan Wang, Herbert Danninger, "Dry sliding behaviour of Molybdenum alloyedsintered steels", Wear 1998: 222, 49-56

[4] Razavizadch K, Davies BL, "The effects of steam treatment on the wear resistance of sintered iron and $\mathrm{Fe}-\mathrm{Cu}$ alloys", Wear, 69, 1981: 113, 355-367

[5] Lorella Ceschini, Giuseppe Palombarini, Giuliano sambogna, Donato Firrao, Giorgio Scavino, Graziano Ubertalli, "Friction and wear behaviour of sintered steels subjected to sliding and abrasion tests", Tribology International 2006: 39, 748-755

[6] Gopinath K, "The influence of speed on the wear of sintered ironbased materials", Wear 1981: 71, 161-178

[7] Zhang Guowei, Ouyang Jinlin, Meng Xiukun, Ma Li, Qi Shang Kui, Meng Xiukun et al., "Reactions during preparation and sliding of sintered Fe-Mo-S wear resistant materials", Wear 1993; 162-164, 450-457

[8] Murakami T, Kaneda K, Nakano N, Mano H, Korenaga A, Sasaki $\mathrm{S}$, "Friction and wear properties of Fe-Mo intermetallic compounds under oil lubrication", Intermetallics 15 (2007) 1573-1581

[9] Tekeli S, Gural A, Ozyurek D, "Dry sliding wear behaviour of low carbon dual phase powder metallurgy steels", Materials and Design. 28 (2007) 1685-1688

[10] Tekeli S, Gural A, "Dry sliding wear behavior of heat treated iron-based powder metallurgy steels with $0.3 \%$ Graphite $+2 \% \mathrm{Ni}$ additions", Materials and Design-28 (2007) 1923-1927

[11] Colaco R, Gordo E, Ruiz-Navas EM, Otasevic M, Vilar R, “A comparative study of the wear behavior of sintered and laser surface melted AISI M42 high speed steel diluted with iron”, Wear, 260, 2006, 949-956

[12] Anton N, Delgodo JL, Velosco F, Torralba JM, "Influence of alloying element additions on tribological behavior of sintered steels with high content in manganese-nickel", Journal of Materials Processing Technology. 143-144, 2003, 475-480

[13] Leheup ER, Deen Zhang, Moon JR, "The effect of density on fretting wear of sintered iron", Wear, 176, 1994, 111-119

[14] Lim SC, Brunton JH, "The unlubricated wear of sintered iron", Wear, 113, 1986, 371-382

[15] Lim SC, Isaacs DC, McClean RH, Bruntont JH, "The unlubricated wear of sintered steels", Tribology International 1987: Vol. 20, No.3, 144-149

[16] Suckchoon Kang, "A study of friction and wear characteristics of Copper-and iron- based sintered materials", Wear, 162-164, 1993, 1123-1128

[17] Dhanasekaran S, Gnanamoorthy R, "Abrasive wear behavior of sintered steels prepared with $\mathrm{MoS}_{2}$ addition”, Wear, 262, 2007, 617 623 